\title{
Can pulse oximetry select patients for screening spirometry?
}

\author{
Eduardo Garcia-Pachon*
}

Department of Internal Medicine, Hospital Vega Baja, Orihuela-Alicante, Spain

\section{KEYWORDS}

Chronic obstructive pulmonary disease; Oximetry; Screening; Spirometry

\section{Introduction}

Many patients with COPD remain undiagnosed, and experts agree that it would be desirable to have some test or intervention that would allow early identification of COPD. A consensus statement from the National Lung Health Education Program in the USA recommended the widespread use of spirometry by primary care physicians in order to identify those patients at high risk of developing COPD [1]. However, controversy remains as to whether spirometry is the ideal test [2] since spirometry is time-consuming, relatively expensive, and needs trained operators. Moreover,

\footnotetext{
*Present address: Section of Pneumology, Hospital General Universitario, E-03203 Elche, Alicante, Spain.

Tel.: +34-96-667-9000; fax: +34-96-667-9108.

E-mail address: egpachon@hotmail.com (E. Garcia-Pachon).
}

Hankinson [3] stated that the indiscriminate use of office spirometry should be reconsidered because of the potential impact of poor quality spirometric recordings. Nevertheless, it is clearly necessary to improve the early recognition of COPD in order to initiate preventable and therapeutic measures $[2,4]$. In addition, an important component of the economic costs of COPD is considered to be due to non-diagnosis or late diagnosis [5].

The measurement of arterial oxygen saturation may be an aid in the identification of these patients since arterial hypoxaemia in COPD occurs frequently and relatively early in the natural history of the disease. The $\mathrm{PaO}_{2}$ in patients with COPD correlates with the forced expiratory volume in $1 \mathrm{~s}$ [6], and, in patients with asthma of varying severity hypoxaemia was related to the degree of obstruction [7]. The portability and 'easy to use' nature of pulse oximeters make them potentially attractive 
for primary care workers [8]. The objective of this study was to investigate whether the measurement of arterial oxygen saturation with a simple and inexpensive method (pulse oximetry) can identify those patients in whom spirometric screening for COPD would be useful, and those patients in whom it would be less useful.

\section{Materials and methods}

Two hundred and ten consecutive patients aged over 40 who attended the Outpatient Pulmonary Clinic were included in the study. All patients were referred to the clinic from their primary care physicians for evaluation of respiratory problems including sleep-disordered breathing. Patients with any of the following criteria were excluded: referral because of dyspnoea; patients presenting with basal dyspnoea score higher than 1 in the Medical Research Council Scale [9]; patients unable to perform spirometry; and patients with haemoptysis, or with suspicion of tuberculosis.

During the visit, while sitting, the patients had an adult articulated finger clip pulse oximeter sensor attached (model 8000 AA, Nonin Medical, Inc.; Plymouth, MN, USA) for at least $3 \mathrm{~min}$. The value of oxygen saturation was recorded when stabilized, and when it oscillated between two values the lower one was considered. Immediately after the visit the patients underwent spirometry performed by a trained technician (blinded to any other data) in a separate room, according to standard criteria [10] with a portable spirometer (PonyGraphic, Cosmed SRL, Rome, Italy). Reference values for the Mediterranean population were used [11]. COPD was defined as a ratio of forced expiratory volume in $1 \mathrm{~s}\left(\mathrm{FEV}_{1}\right)$ to forced vital capacity (FVC) of less than 0.7, and patients were classified according to a recent international consensus [12].

Pearson's correlation test was calculated between oxygen saturation and the spirometric variables. Sensitivity, specificity, positive likelihood ratio, and negative likelihood ratio were calcu- lated at several values of oxygen saturation for the following:

(1) Diagnosing COPD ( $\left.\mathrm{FEV}_{1} / \mathrm{FVC}<70 \%\right)$ in all the patients; and independently in the group of patients with a history of smoking more than 20 pack-years.

(2) For detecting significant COPD $\left(\mathrm{FEV}_{1}<50 \%\right.$ of predicted, stage IIB and III in the GOLD classification [12]).

(3) For detecting patients with $\mathrm{FEV}_{1}<80 \%$ of predicted value.

\section{Results}

One hundred and fifty-four patients were men $(73 \%)$, and 56 were women (27\%), mean age 62 years (S.D. 11years). One hundred and ten had a history of smoking of more than 20 pack-years. Fifty-eight patients had COPD (prevalence, 28\%); 26 of them had an $\mathrm{FEV}_{1}<50 \%$ of predicted. Of the 210 patients, $103(49 \%)$ had an $\mathrm{FEV}_{1}$ value $<80 \%$ of predicted value. There was a significant $(P<0.001$ in all cases) correlation between the oxygen saturation and the spirometric variables $\left(\mathrm{FEV}_{1}\right.$ percentage of predicted, $r=0.41$; FVC percentage of predicted, $r=0.40$; and $\mathrm{FEV}_{1} / \mathrm{FVC}, r=0.34$ ).

The diagnostic value of oxygen saturation at several values (from 95 to $99 \%$ ) for diagnosing COPD is detailed in Table 1. Using a cut-off value of $<98 \%$ oxygen saturation, sensitivity for COPD diagnosis was $79 \%$ and specificity $37 \%$. In order to ensure $100 \%$ detection of all cases of COPD the $\mathrm{SpO}_{2}$ cut-off value should be $<99 \%$, but then the specificity is only $7 \%$. The calculations in the 110 smoking patients showed similar findings; withra cut-off value of $<98 \%$ oxygen saturation, sensitivity of COPD diagnosis was $76 \%$ and specificity $31 \%$. All of the 45 smokers with COPD had an oxygen saturation level $<99 \%$ but so did 64 of the 65 smokers without COPD (sensitivity $100 \%$, specificity $2 \%$ ). When more severe COPD was considered $\left(\mathrm{FEV}_{1}<50 \%\right)$, for an oxygen saturation $<98 \%$ sensitivity of COPD diagnosis was $77 \%$; consequently 6 of the 26 patients with severe COPD were

Table 1 Diagnostic value of oxygen saturation for detecting obstructive airway disease $\left(\mathrm{FEV}_{1} / \mathrm{FVC}<0.70\right)$.

\begin{tabular}{lllll}
\hline $\begin{array}{l}\text { Arterial oxygen } \\
\text { saturation (\%) }\end{array}$ & Sensitivity (\%) & Specificity (\%) & $\begin{array}{l}\text { Positive } \\
\text { likelihood ratio }\end{array}$ & $\begin{array}{l}\text { Negative } \\
\text { likelihood ratio }\end{array}$ \\
\hline$<95$ & & & 2.77 & 0.77 \\
$<96$ & 31 & 89 & 2.05 & 0.66 \\
$<97$ & 50 & 76 & 1.36 & 0.67 \\
$<98$ & 64 & 37 & 1.25 & 0.56 \\
$<99$ & 79 & 7 & 1.07 & 0.00 \\
\hline
\end{tabular}


Table 2 Diagnostic value of oxygen saturation for detecting $\mathrm{FEV}_{1}<80 \%$ of predicted.

\begin{tabular}{lllll}
\hline $\begin{array}{l}\text { Arterial oxygen } \\
\text { saturation (\%) }\end{array}$ & Sensitivity (\%) & Specificity (\%) & $\begin{array}{l}\text { Positive } \\
\text { likelihood Ratio }\end{array}$ & $\begin{array}{l}\text { Negative } \\
\text { likelihood ratio }\end{array}$ \\
\hline$<95$ & & & 4.20 & 0.76 \\
$<96$ & 28 & 93 & 2.27 & 0.68 \\
$<97$ & 45 & 80 & 1.32 & 0.77 \\
$<98$ & 53 & 60 & 1.19 & 0.68 \\
$<99$ & 74 & 88 & 1.07 & 0.23 \\
\hline
\end{tabular}

not detected with this method. The diagnostic values of oxygen saturation for detecting $\mathrm{FEV}_{1}<80 \%$ are shown in Table 2. Results were similar to those for diagnosing COPD in terms of the $\mathrm{FEV}_{1} \mathrm{FVC}$ ratio.

\section{Discussion}

The prevalence of COPD in several studies [13-18] has been found to be between 4.5 and $9.9 \%$. In a large study [13] the prevalence of COPD in people aged 40-70 years, non-selected for respiratory symptoms or tobacco exposition, was $9.1 \%$. Importantly, $78 \%$ of COPD patients had not been previously diagnosed, including $50 \%$ of those with more severe disease [13]. For early identification of COPD patients the widespread use of office spirometry by primary care physicians has been recommended [1]. Nevertheless, this strategy is controversial because spirometry needs experienced operators and there can be difficulty in obtaining good spirometric recordings in general practice even after training workshops [19].

The objective of this study was to evaluate whether the measurement of arterial oxygen saturation by pulse oximetry (a simple, rapid, and inexpensive-method that does not require experienced Operators) can selecepatients who are suitable for screening spirometry with a view to improving diagnosis rates of COPD. These results show that, in order to detect all patients with COPD it is necessary to have a cut-off value for $\mathrm{SpO}_{2}$ at $<99 \%$, a value so high that we can avoid performing spirometry in only $6.5 \%$ of those patients who do not have COPD. With a lower cut-off value (oxygen saturation $<98 \%$ ) we can detect $79 \%$ of COPD patients, with a specificity of $37 \%$. When smokers alone are considered, results in terms of sensitivity and specificity are no better.

A possible use of pulse oximetry might be to detect patients with more severe COPD, who are frequently undiagnosed. However, from these results, pulse oximetry does not achieve this objective. 23\% of the patients with significant COPD $\left(\mathrm{FEV}_{1}<50 \%\right.$ predicted) remain undetected when using a cut-off value for $\mathrm{SpO}_{2}$ of $98 \%$. When pulse oximetry was used for detecting those patients with $\mathrm{FEV}_{1}<80 \%$ predicted (both of obstructive or non-obstructive origin) results were similarly poor.

These results should be considered in the context of other means for selecting patients for screening spirometry. Several physical signs have been evaluated for the detection of COPD, and some of them alone or in association with medical history data may be very useful for this purpose [20-23]. In fact, by using an overall clinical impression for diagnosing COPD, reported values [21-24] of sensitivity (50-64\%) and specificity (64-93\%), and likelihood ratios (positive 1.4-7.3, negative 0.4-0.8) are of interest. Although these studies were performed with different inclusion criteria, their results are no worse than ours obtained by using pulse oximetry.

In conclusion, although arterial oxygen saturation levels correlate with $\mathrm{FEV}_{1}$, pulse oximetry is not a useful test for the selection of patients for screening spirometry,

\section{References}

[1] Ferguson GT, Enright PL, Buist AS, Higgins MW. Office spirometry for lung health assessment in adults: a consensus statement from the National Lung Health Education Program. Chest 2000;117:1146-61.

[2] Enright PL, Crapo RO. Controversies in the use of spirometry for early recognition and diagnosis of chronic obstructive pulmonary disease in cigarette smokers. Clin Chest Med 2000;21:645-52.

[3] Hankinson JL. Office spirometry. Does poor quality render it impractical? [Editorial]. Chest 1999;116:276-7.

[4] Van Schayck O, Rabe KF, Rudolf M. COPD: the role of primary care in effective diagnosis, treatment and management. Prim Care Resp J 2003;12:16-20.

[5] Miravitlles $M$, Figueras $M$. The cost of chronic obstructive pulmonary disease in Spain: options for optimising resources [in Spanish]. Arch Bronconeumol 2001;37:38893.

[6] Lim S, MacRae KD, Seed WA, Roberts CM. The value of forced expiratory volume in $1 \mathrm{~s}$ in screening subjects with stable COPD for $\mathrm{PaO}_{2}<7.3 \mathrm{kPa}$ qualifying for long-term oxygen therapy. Respir Med 1998;92:1122-6. 
[7] McFadden ER, Lyons HA. Arterial blood gas tension in asthma. N Engl J Med 1968;42:238-49.

[8] Chavannes N. Pulse oximetry and respiratory disease in primary care [Editorial]. Prim Care Resp J 2003;12:2-3.

[9] Mahler DA, Wells CK. Evaluation of clinical methods for rating dyspnea. Chest 1988;93:580-6.

[10] American Thoracic Society. Standardization of spirometry. Am J Respir Crit Care Med 1995;152:1107-36.

[11] Roca J, Sanchis J, Agusti-Vidal A, et al. Spirometric reference values from a Mediterranean population. Bull Eur Physiopathol Respir 1986;22:217-24.

[12] Pauwels RA, Buist S, Calverley PMA, et al. Global strategy for the diagnosis, management, and prevention of chronic obstructive pulmonary disease. Am J Respir Crit Care Med 2001;163:1256-76.

[13] Sobradillo V, Miravitlles M, Gabriel R, et al. Geographical variations in prevalence and underdiagnosis of COPD. Results of the IBERPOC multicentre epidemiological study. Chest 2000;118:981-9.

[14] Lange P, Groth S, Nyboe J, et al. Chronic obstructive lung disease in Copenhagen cross-sectional epidemiological aspects. J Intern Med 1989;226:25-32.

[15] Bakke PS, Baste V, Hanoa R, Gulsvik S. Prevalence of obstructive lung disease in a general population: relation to occupational title and exposure to some airbone agents. Thorax 1991;46:863-70.

[16] Brotons B, Perez JA, Sanchez-Toril F, et al. Prevalence of chronic obstructive lung disease and asthma: a cross- sectional study [in Spanish]. Arch Bronconeumol 1994;30: 149-52.

[17] Renwick DS, Conolly MJ. Prevalence and treatment of chronic airways obstruction in adults over the age of 45 . Thorax 1996;51:164-8.

[18] Lacasse Y, Brooks D, Goldstein RS. Trends in the epidemiology of COPD in Canada, 1980 to 1995. Chest 1999;116:30613.

[19] Eaton T, Withy S, Garrett JE, et al. Spirometry in primary care practice: the importance of quality assurance and the impact of spirometry workshops. Chest 1999;116:41623.

[20] Badgett RG, Tanaka DJ, Hunt DK, et al. Can moderate chronic obstructive pulmonary disease be diagnosed by historical and physical findings alone. Am J Med 1993;94:18896.

[21] Badgett RG, Tanaka DJ, Hunt DK, et al. The clinical evaluation for diagnosing obstructive airways disease in high-risk patients. Chest 1994;106:1427-31.

[22] Holleman DR, Simel DL. Does the clinical examination predict airflow limitation. JAMA 1995;273:313-9.

[23] Garcia-Pachon E. Paradoxical movement of lateral rib margin (Hoover sign) for detecting obstructive airway disease. Chest 2002;122:651-5.

[24] McAlister FA, Strauss SE, Sackett DL. for the CARE-COAD1 Group. Why we need large, simple studies of the clinical examination: the problem and a proposed solution. Lancet 1999;354:1721-4.

Available online at www.sciencedirect.com

science $\boldsymbol{D}$ Direct.

Available online at http://www.thepcrj.com

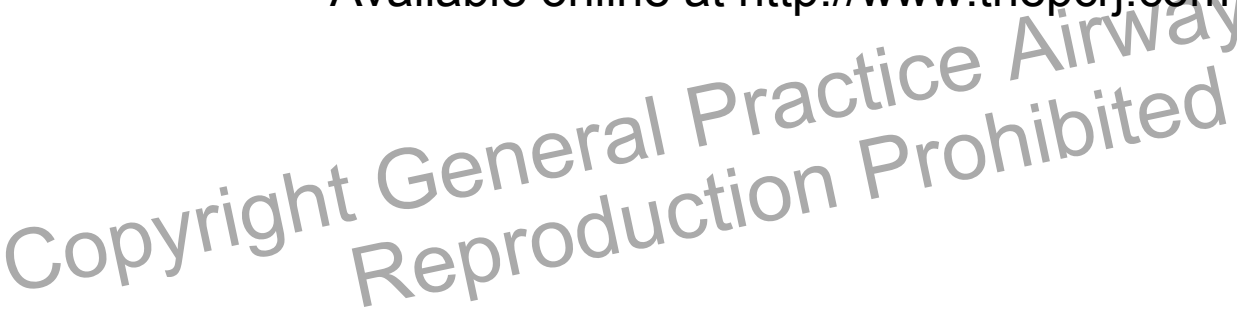

